\title{
Sistem Pendukung Keputusan Penerimaan Jurnalis Menerapkan Multi- Objective Optimization On The Basis Of Ratio Analysis (MOORA)
}

\author{
Aldi Muharsyah ${ }^{1}$, Soraya Rahma Hayati ${ }^{1}$, M. Ikhsan Setiawan ${ }^{2}$, Heri Nurdiyanto ${ }^{3}$, Yuhandri ${ }^{4}$ \\ ${ }^{1}$ Mahasiswa Program Studi Teknik Informatika STMIK Budi Darma, Medan, Indonesia \\ ${ }^{2}$ Fakultas Teknik Sipil, Universitas Narotama, Surabaya, Indonesia \\ ${ }^{3}$ Program Studi Teknik Informatika, STMIK Dharma Wacana, Lampung, Indonesia \\ ${ }^{4}$ Fakultas Ilmu Komputer, Universitas Putra Indonesia YPTK, Padang, Indonesia
}

\begin{abstract}
Abstrak
Sistem pendukung keputusan adalah bagian dari sistem informasi berbasis komputer (termasuk sistem berbasis pengetahuan (manajemen pengetahuan)) yang dipakai untuk mendukung pengambilan keputusan dalam suatu organisasi atau perusahaan. Sistem pendukung keputusan memberikan suatu keputusan yang bersifat semiterstruktur, dimana tidak seorangpun tahu secara pasti bagaimana keputusan seharusnya dibuat. Perengkrutan penerimaan karyawan pada PT.Waspada Medan selalu melalui beberapa seleksi ketat sebelum ditetapkan diterima sebagai karyawan pada PT.Waspada Medan. Ada beberapa kriteria yang harus dimiliki setiap peserta sebagai syarat untuk menjadi karyawan PT.Waspada Medan. Untuk mendapatkan peserta terbaik maka pihak PT.Waspada Medan membutuhkan sebuah sistem pendukung keputusan. Pada penelitian ini penulis menerapkan Multi-Objective Optimization on the basis of Ratio Analysis (MOORA Method) sebagai metode yang akan diterapkan didalam aplikasi sistem pendukung keputusan.
\end{abstract}

Kata kunci: Sistem Pendukung Keputusan, Multi-Objective Optimization, Ratio Analysis, MOORA

\section{Abstract}

Decision support systems are part of computer-based information systems (including knowledge-based systems) that are used to support decision making within an organization or company. The decision support system provides a semi-structured decision, where no one knows for sure how decisions should be made. Recruitment of employee recruitment in PT.Waspada Medan always through some tight selection before set accepted as employees at PT.Waspada Medan. There are several criteria that must be owned by each participant as a requirement to become an employee of PT.Waspada Medan. To get the best participants then the PT.Waspada Medan requires a decision support system. In this study, the authors apply Multi-Objective Optimization on the basis of Ratio Analysis (MOORA Method) as the method to be applied in the application of decision support system.

Keywords: Decision Support System, Multi-Objective Optimization, Ratio Analysis, MOORA

\section{PENDAHULUAN}

Setiap perusahan membutuhkan efisien dan efektifitas waktu didalam setiap kegiatan operasionalnya, tidak terkecuali dalam penerimaan karyawannya. Dalam setiap kegiatan proses penerimaan karyawan baru banyak sekali terdapat permasalahan antara lain terlalu banyak jumlah pencarian kerja, sehingga perusahaan kesulitan dalam menentukan mana calon karyawan yang mempunyai kemampuan ataupun kompetensi dibidang perkantoran. Dalam proses pencarian atau penerimaan karyawan baru, data yang diperoleh dari hasil seleksi masih menggunakan cara manual yang sangat menguras waktu dan tenaga bagi Human Resources Department (HRD) perusahaan.

Sebagai calon karyawan yang memiliki pendidikan, umur dan nilai yang memuaskan akan tetapi mereka tidak mempunyai pengalaman kerja ataupun memiliki pengalaman kerja tetapi pendidikannya tidak sesuai dengan kriteria yang ditentukan oleh perusahaan atau mempunyai pendidikan, umur, nilai dan pengalaman kerja yang bagus tetapi disaat wawancara dia tidak menjawab sesuai yang diharapkan perusahaan juga menjadi permaslahan bagi Human Resources Department (HRD) dalam melakukan penyeleksian calon karyawan.

Pengambilan keputusan untuk menetnukan apakah calon karyawan dapat diterima atau tidak didasari beberapa kriteria yang ditetapkan oleh perusahaan. Untuk menghindari terjadinya kesalahan pengambilan keputusan yang dihasilkan diperlukan suatu Sistem Pendukung Keputusan (SPK) yang dapat membantu Human Resources Department (HRD) dalam memutuskan calon karyawan mana yang akan diterima. Sistem pendukung keputusan merupakan suatu sistem menggunakan model yang dibangununtuk membantu menyelesaikan masalahmasalah semi terstruktur

Beberapa metode yang dapat diterpakan dalam sistem pendukung keputusan diantaranya, metode MultiObjective Optimization on the basis of Ratio Analysis (MOORA) metode Weighted Product (WP), metode Simple Additive Weighting (SAW), Weighted Sum Model (WSM)[1] merupakan metode yang tergolong sederhana penyelesaiannya bila dibandingkan dengan Technique For Orders Preference By Similarity To Ideal Solution (TOPSIS)[2], Elimination and Choice Expressing Reality (ELECTRE) ataupun Promethee II, EXPROM II. 
Metode MOORA dipilih dikarenakan kemudahannya dalam mencari alternatif terbaik dari beberapa alternatif yang ada[3].

Berdasarkan kriteria yang telah ditentukan maka metode ini dapat melakukan perangkingan terhadap setiap atribut dan menghasilkan alternatif yang berhak menjadi karyawan pada PT. Waspada Medan berdasarkan kriteria-kriteria yang ditentukan. Apabila proses pangambilan keputusan tersebut dibantu oleh sebuah sistem pendukung keputusan yang terkomputerisasi, subjektivitas dalam pengambilan keputusan diharapkan bisa dikurangi dan diganti dengan pelaksanaan seluruh kriteria bagi calon karyawan.

Dengan demikian hanya peserta yang benar-benar layaklah yang diharapkan akan terpilih. Namun demikian dalam sistem ini yang memegang peranan penting adalah pengambil keputusan karena sistem hanya menyediakan alternatif keputusan, sedangkan keputusan akhir tetap ditentukan oleh decision maker (pengambil keputusan).

\section{TEORITIS}

\subsection{Sistem Pendukung Keputusan}

Sistem Pendukung Keputusan Sistem pendukung keputusan adalah sistem berbasis komputer yang mampu memecahkan masalah manajemen dalam menghasilkan alternatif terbaik untuk mendukung keputusan yang diambil oleh pengambil keputusan[4].

\subsection{Penerimaan Karyawan}

Kegiatan yang masih berkaitan dengan perencanaan SDM adalah penerimaan atau pengadaan tenaga kerja. Pengadaan tenaga kerja itu sendiri adalah suatu proses untuk mendapatkan tenaga yang berkualitas dan memberikan harapan yang baik pada calon tenagakerja tersebut untuk membuat lamaran kerja guna bekerja pada instansi/perusahaan tersebut. Proses penerimaan dimulai dari mencari dan menarik pelamar yang mampu melakukan suatu pekerjaan sampai adanya lamaran masuk.

Sumber Daya Manusia (SDM) merupakan sumber daya yang paling penting bagi organisasi. Salah satu proses yang paling penting bagi perusahaan adalah proses rekrutmen dan seleksi sumber daya manusia. Pada kenyataannya pengambilan keputusan secara efisien dan efektif pada saat melakukan seleksi terhadap sumber daya manusia bukanlah hal yang mudah, maka diperlukan suatu Sistem Pendukung Keputusan (SPK) untuk membantu memecahkan masalah tersebut[5].

\subsection{Multi-Objective Optimization on the basis of Ratio Analysis (MOORA)}

Multi-Objective Optimization on the basis of Ratio Analysis (MOORA) adalah multiobjektif sistem mengoptimalkan dua atau lebih attribut yang saling bertentangan secara bersamaan. Metode ini diterapkan untuk memecahkan masalah dengan perhitungan matematika yang kompleks. Moora diperkenalkan oleh Brauers dan Zavadskas pada tahun 2006.

Pada awalnya metode ini diperkenalkan oleh Brauers pada tahun 2004 sebagai "Multi-Objective Optimization" yang dapat digunakan untuk memecahkan berbagai masalah pengambilan keputusan yang rumit pada lingkungan perusahaan. Metode moora diterapkan untuk memecahkan banyak permasalahan ekonomi, manajerial dan konstruksi pada sebuah perusahaan maupun proyek[6].

Adapun langkah pemrosesan MOORA[6][4][5], dapat dilihat berikut ini:

Langkah 1: Normalisasi matrik keputusan

$$
\boldsymbol{X}_{i j}^{*}=X_{i j} / \sqrt{\left[\sum_{i=1}^{m} X_{i j}^{2}\right]}
$$

Langkah 2: Mengurangi nilai maximax dan minimax

$$
Y_{i}=\sum_{j=1}^{g} w_{j} x_{i j}^{*}-\sum_{j=g+1}^{n} w_{j} w_{i j}^{*}
$$

Langkah 3: Menentukan rangkin dari hasil perhitungan MOORA

Nilai yang terbaik dari alternatif yang dihitung merupakan nilai yang tertinggi

\section{ANALISA DAN PEMBAHASAN}


Dalam metode (MOORA) terdapat kriteria-kriteria yang akan dijadikan bahan perhitungan pada proses penilaian. Hal itu dimaksudkan untuk menentukan karyawan yang akan diterima dalam proses seleksi penerimaan karyawan. Dalam hal ini dibutuhkan kriteria-kriteria yang terlihat pada tabel 1 .

Tabel 1. Kriteria

\begin{tabular}{|c|l|l|l|}
\hline Kriteria & Keterangan & \multicolumn{2}{|c|}{ Bobot } \\
\hline $\mathrm{C}_{1}$ & IPK & 0,25 & Benefit \\
\hline $\mathrm{C}_{2}$ & Umur & 0,25 & Cost \\
\hline $\mathrm{C}_{3}$ & Pengalaman Kerja & 0,2 & Benefit \\
\hline $\mathrm{C}_{4}$ & Nilai Psikotest & 0,15 & Benefit \\
\hline $\mathrm{C}_{5}$ & Nilai Wawancara & 0,15 & Binefit \\
\hline
\end{tabular}

Untuk alternatif (kandidat) akan diseleksi jurnalis terdiri dari 5 orang yaitu :

Tabel 2. Alternatif

\begin{tabular}{|c|l|}
\hline Alternatif & Nama \\
\hline $\mathrm{A}_{1}$ & Rudi \\
\hline $\mathrm{A}_{2}$ & Putri \\
\hline $\mathrm{A}_{3}$ & Sugi \\
\hline $\mathrm{A}_{4}$ & Ihsan \\
\hline $\mathrm{A}_{5}$ & Yuni \\
\hline
\end{tabular}

Tabel 3 berisi dari data rating kecocokan antar alternatif dan kriteria.

Tabel 3. Nilai setiap Alternatif pada setiap kriteria

\begin{tabular}{|l|l|l|l|l|l|}
\hline \multirow{2}{*}{ Alternatif } & \multicolumn{4}{l}{ Kriteria } \\
\cline { 2 - 6 } & $\mathrm{C}_{1}$ & $\mathrm{C}_{2}$ & $\mathrm{C}_{3}$ & $\mathrm{C}_{4}$ & $\mathrm{C}_{5}$ \\
\hline $\mathrm{A}_{1}$ & 2,57 & 20 & 2 & 50 & 60 \\
\hline $\mathrm{A}_{2}$ & 3,02 & 18 & 4 & 87 & 70 \\
\hline $\mathrm{A}_{3}$ & 2,95 & 25 & 3 & 67 & 60 \\
\hline $\mathrm{A}_{4}$ & 3,23 & 35 & 2 & 80 & 60 \\
\hline $\mathrm{A}_{5}$ & 3,38 & 40 & 5 & 80 & 70 \\
\hline Optimum & Max & Min & Max & Max & Max \\
\hline
\end{tabular}

Adapun langkah-langkah penentuan penerimaan calon karyawan baru dengan menggunakan metode (MOORA) adalah sebagai berikut :

1. Membuat matrix keputusan $X_{\mathrm{ij}}$ berdasarkan tabel3, sebagai berikut :

$$
X=\left[\begin{array}{lllll}
2,57 & 20 & 2 & 50 & 60 \\
3,02 & 18 & 4 & 87 & 70 \\
2,95 & 25 & 3 & 67 & 60 \\
3,23 & 35 & 2 & 80 & 60 \\
3,38 & 40 & 5 & 80 & 70
\end{array}\right]
$$

Kemudian membentuk matrix yang dinormalisasikan dengan menggunakan persamaan 1

Hasil dari Normalisasi matriks $\mathrm{X}$ diperoleh matrik $X_{I J}^{*}$

$\mathrm{C}_{1}=\sqrt{2,57^{2}+3,02^{2}+2,95^{2}+3,23^{2}+3,38^{2}}$

$$
=6,80331
$$

$\mathrm{A}_{11}=2,57 / 6,80331=0,37775$

$\mathrm{A}_{21}=3,02 / 6,80331=0,44390$

$\mathrm{A}_{31}=2,95 / 6,80331=0,43361$

$\mathrm{A}_{41}=3,23 / 6,80331=0,47476$

$A_{51}=3,38 / 6,80331=0,49681$ 


$$
\begin{aligned}
\mathrm{C}_{2} & =\sqrt{20^{2}+18^{2}+25^{2}+35^{2}+40^{2}} \\
& =64,60650 \\
\mathrm{~A}_{12} & =20 / 64,60650=0,30956 \\
\mathrm{~A}_{22} & =18 / 64,60650=0,27860 \\
\mathrm{~A}_{32} & =25 / 64,60650=0,38695 \\
\mathrm{~A}_{42} & =35 / 64,60650=0,54174 \\
\mathrm{~A}_{52} & =40 / 64,60650=0,61913 \\
\mathrm{C}_{3} & =\sqrt{2^{2}+4^{2}+3^{2}+2^{2}+5^{2}} \\
& =7,61577 \\
\mathrm{~A}_{13} & =2 / 7,61577=0,26261 \\
\mathrm{~A}_{23} & =4 / 7,61577=0,52522 \\
\mathrm{~A}_{33} & =3 / 7,61577=0,39391 \\
\mathrm{~A}_{43} & =2 / 7,61577=0,26261 \\
\mathrm{~A}_{53} & =5 / 7,61577=0,65653 \\
\mathrm{C}_{4} & =\sqrt{50^{2}+87^{2}+67^{2}+80^{2}+80^{2}} \\
& =165,40253 \\
\mathrm{~A}_{14} & =50 / 165,40253=0,30229 \\
\mathrm{~A}_{24} & =87 / 165,40253=0,52598 \\
\mathrm{~A}_{34} & =67 / 165,40253=0,40507 \\
\mathrm{~A}_{44} & =80 / 165,40253=0,48366 \\
\mathrm{~A}_{54} & =80 / 165,40253=0,48366 \\
\mathrm{C}_{5} & =\sqrt{60^{2}+70^{2}+60^{2}+60^{2}+70^{2}} \\
& =143,5270 \\
\mathrm{~A}_{15} & =60 / 143,5270=0,41803 \\
\mathrm{~A}_{25} & =70 / 143,5270=0,48771 \\
\mathrm{~A}_{35} & =60 / 143,5270=0,41803 \\
\mathrm{~A}_{45} & =60 / 143,5270=0,41803 \\
\mathrm{~A}_{55} & =70 / 143,5270=0,48771 \\
&
\end{aligned}
$$

Hasil perhitungan dari normalisasi matrix $\mathrm{X}_{\mathrm{ij}}^{*}$ adalah

$$
X_{i j}^{*}\left[\begin{array}{lllll}
0,37775 & 0,30956 & 0,26261 & 0,30229 & 0,41803 \\
0,44390 & 0,27860 & 0,52522 & 0,52598 & 0,48771 \\
0,43361 & 0,38695 & 0,39391 & 0,40507 & 0,41803 \\
0,47476 & 0,54174 & 0,26261 & 0,48366 & 0,41803 \\
0,49681 & 0,61913 & 0,65653 & 0,48366 & 0,48771
\end{array}\right]
$$

Kemudian menentukan nilai $\mathrm{Y}_{\mathrm{i}}$ dengan menggunakan persamaan 4

$$
\left[\begin{array}{lllll}
0,37775, & 0,30956 & 0,26261 & 0,30229 & 0,41803 \\
0,44390 & 0,27860 & 0,52522 & 0,52598 & 0,48771 \\
0,43361 & 0,38695 & 0,39391 & 0,40507 & 0,41803 \\
0,47476 & 0,54174 & 0,26261 & 0,48366 & 0,41803 \\
0,49681 & 0,61913 & 0,65653 & 0,48366 & 0,48771
\end{array}\right] W_{i j}^{*}
$$

Hasil setelah perhitungan

$\left[\begin{array}{lllll}0,09443 & 0,07739 & 0,05252 & 0,04534 & 0,06270 \\ 0,11097 & 0,89734 & 0,10504 & 0,07889 & 0,07315 \\ 0,10840 & 0,09673 & 0,07878 & 0,06076 & 0.06270 \\ 0,11869 & 0,13543 & 0,05252 & 0,07254 & 0,06270 \\ 0,12420 & 0,40379 & 0,13130 & 0,07254 & 0,07315\end{array}\right]$

Berikut merupakan hasil Yi yang diproses dari persamaan 2, terlihat pada tabel 4.

Tabel 4. $\mathrm{Y}_{\mathrm{i}}$ List 


\begin{tabular}{|c|c|c|c|}
\hline Alternatif & Maximum $\left(\mathrm{C}_{1}+\mathrm{C}_{3}+\mathrm{C}_{4}+\mathrm{C}_{5}\right)$ & Minimum $\left(\mathrm{C}_{2}\right)$ & $\mathrm{Y}_{\mathrm{i}}=$ Max-Min \\
\hline $\mathrm{A}_{1}$ & 0,25499 & 0,07739 & 0,1776 \\
\hline $\mathrm{A}_{2}$ & 0,36805 & 0,89734 & 0,52929 \\
\hline $\mathrm{A}_{3}$ & 0,31064 & 0,09673 & 0,21391 \\
\hline $\mathrm{A}_{4}$ & 0,30645 & 0,13543 & 0,17102 \\
\hline $\mathrm{A}_{5}$ & 0,40119 & 0,40379 & 0,0026 \\
\hline
\end{tabular}

Tabel ke 5 merupakan tabel perhitungan dan telah dirangking dari yang tertinggi sampai yang terendah

Tabel 5. Perangkingan

\begin{tabular}{|c|c|c|}
\hline Alternatif & Hasil & Rangking \\
\hline Putri & 0,52929 & 1 \\
\hline Sugi & 0,21391 & 2 \\
\hline Rudi & 0,1776 & 3 \\
\hline Ihsan & 0,17102 & 4 \\
\hline Yuni & 0,0026 & 5 \\
\hline
\end{tabular}

Dari hasil perhitungan tabel alternatif $\mathrm{A}_{2}$ (Putri) merupakan nilai yang tertinggi dibandingkan dengan nilai alternatif $\mathrm{A}_{5}$ (Yuni). Maka yang diterima sebagai karyawan PT.Waspada Medan adalah Putri dengan nilai tertinggi

\section{KESIMPULAN}

Berdasarkan hasil dari penelitian yang penulis lakukan penerapan metode Multi-Objective Optimization on the basis of Ratio Analysis cukup mudah digunakan sebagai cara untuk penentuan jurnalis baru karena langkahlangkah penyelesaiannya cukup sederhana

\section{REFERENCES}

[1] Mesran, Suginam, S. D. Nasution, and A. P. U. Siahaan, "PENERAPAN WEIGHTED SUM MODEL ( WSM ) DALAM PENENTUAN PESERTA JAMINAN," J. Ris. Sist. Inf. dan Tek. Inform., vol. 2, no. 1, pp. 40-47, 2017.

[2] G. Ginting, Fadlina, Mesran, A. P. U. Siahaan, and R. Rahim, "Technical Approach of TOPSIS in Decision Making," Int. J. Recent Trends Eng. Res., vol. 3, no. 8, pp. 58-64, 2017.

[3] H. Nurdiyanto and Heryanita Meilia, "SISTEM PENDUKUNG KEPUTUSAN PENENTUAN PRIORITAS PENGEMBANGAN INDUSTRI KECIL DAN MENENGAH DI LAMPUNG TENGAH MENGGUNAKAN ANALITICAL HIERARCHY PROCESS (AHP)," in Seminar Nasional Teknologi Informasi dan Multimedia 2016, 2016, no. February, pp. 1-7.

[4] T.-P. Turban, E., Aronson, J., \& Liang, Decision Support Systems And Inteligence System. US: Prentice-Hall, 2005.

[5] D. M. Ariyanti, F. Agus, and D. M. Khairina, "Sistem Pendukung Keputusan Untuk Seleksi Penerimaan Dan Penentuan Posisi Karyawan," J. Inform. Mulawarman, vol. 10, no. 1, 2015.

[6] Mesran, R. K. Hondro, M. Syahrizal, A. P. U. Siahaan, R. Rahim, and Suginam, "Student Admission Assessment using Multi-Objective Optimization on the Basis of Ratio Analysis (MOORA)," J. Online Jar. COT POLIPT, vol. 10, no. 7, pp. 1-6, 2017.

[7] P. Karande and S. Chakraborty, "Application of multi-objective optimization on the basis of ratio analysis (MOORA) method for materials selection," Mater. Des., vol. 37, no. 2, pp. 317-324, 2012.

[8] Onur Önay and B. F. Yıldırım, "Evaluation of NUTS Level 2 Regions of Turkey by TOPSIS , MOORA and VIKOR 1," Int. J. Humanit. Soc. Sci., vol. 6, no. 1, pp. 212-221, 2016.

[9] S. Dian Utami Sutiksno, P. Rufaidah, H. Ali, and W. Souisa, "A Literature Review of Strategic Marketing and The Resource Based View of The Firm," Int. J. Econ. Res., vol. 14, no. 8, pp. 59-73, 2017.

[10] S. Kusumadewi, S. Hartati, A. Harjoko, and R. Wardoyo, Fuzzy Multi-Attribute Decision Making (Fuzzy MADM). Yogyakarta: Graha Ilmu, 2006.

[11] M. Sumitre and R. Kurniawan, "Rancang Bangun Sistem Pendukung Keputusan Seleksi Penerimaan Tenaga Pengajar Dengan Metode Fuzzy Inference System (FIS) Mamdani," J. Inform., vol. 14, no. 1, pp. 61-71, 2014.

[12] J. Simarmata, Rekayasa Perangkat Lunak. Yogyakarta: Andi, 2010.

[13] J. Simarmata, Pengenalan Teknologi Komputer dan Informasi. Yogyakarta: Andi, 2006.

[14] M. I. Setiawan et al., "Business Centre Development Model of Airport Area in Supporting Airport Sustainability in Indonesia," J. Phys. Conf. Ser., vol. 954, no. 1, p. 12024, 2018.

[15] N. W. Al-Hafiz, Mesran, and Suginam, "Sistem Pendukung Keputusan Penentukan Kredit Pemilikan Rumah Menerapkan MultiObjective Optimization on the Basis of Ratio Analysis ( Moora )," KOMIK (Konferensi Nas. Teknol. Inf. dan Komputer), vol. I, no. 1, pp. 306-309, 2017.

[16] D. Handoko, M. Mesran, S. D. Nasution, Y. Yuhandri, and H. Nurdiyanto, "Application Of Weight Sum Model (WSM) In Determining Special Allocation Funds Recipients," IJICS (International J. Informatics Comput. Sci., vol. 1, no. 2, pp. 31-35, 2017.

[17] T. Murti, L. A. Abdillah, and M. Sobri, "Sistem Penunjang Keputusan Kelayakan Pemberian Pinjaman Dengan Metode Fuzzy Tsukamoto," Semin. Nas. Inov. dan Tren (SNIT)2015, pp. 252-256, 2015.

[18] A. J. Putra, L. A. Abdillah, and H. Yudiastuti, "Penentuan sekolah dasar negeri terbaik kota Palembang dengan metode weighted sum model (WSM) dan weighted product model (WPM) menggunakan visual basic.net 2015," Sentikom, no. September, pp. 1-6, 2016. 